THE OLIVIERI SYMPOSIUM

\title{
Supporting whistleblowers in academic medicine: training and respecting the courage of professional conscience
}

\author{
T Faunce, S Bolsin, W-P Chan
}

J Med Ethics 2004;30:40-43. doi: 10.1136/jme.2003.006940

Conflicts between the ethical values of an organisation and the ethical values of the employees of that organisation can often lead to conflict. When the ethical values of the employee are considerably higher than those of the organisation the potential for catastrophic results is enormous. In recent years several high profile cases have exposed organisations with ethical weaknesses. Academic medical institutions have exhibited such weaknesses and when exposed their employees have almost invariably been vindicated by objective inquiry. The mechanisms that work to produce such low ethical standards in what should be exemplary organisations are well documented and have been highlighted recently. The contribution of elements of medical training in eroding ethical standards of medical students have also been emphasised recently and strategies proposed to reduce or reverse this process. The ability to rapidly change the ethical and professional culture of graduate medical trainees may help to deal with some of the perceived problems of declining ethical standards in academic medicine.

See end of article for authors' affiliations

Correspondence to: Associate Professor S Bolsin, Department of Perioperative Medicine Geelong Hospital, Geelong, Victoria, Australia; steveb@ barwonhealth.org.au

Accepted for publication 27 October 2003
A $\mathrm{n}$ active conscience, like competence, is a virtue expected in any profession for, by their nature, professions should involve a measure of altruism in serving the public good. Yet, are we doing enough to train, encourage, and support professionals to follow their conscience and, if necessary, criticise internal regulatory decisions and processes, not only in clinical, but in academic medicine?

Recently, Time magazine selected three female American whistleblowers as its 2002 "Persons of the Year". The supporting article highlighted the global need for corporate and institutional management to value staff whose conscience is sufficiently active to make them challenge what they see as unsafe, unethical or inefficient work practices that have been inadequately considered by their institution's own regulatory system. The awards to Cynthia Cooper, head of the internal audit unit at Worldcom, Sherron Watkins, vice president at ENRON, and Coleen Rowley, a midlevel lawyer at a field office in the Federal Bureau of Investigation (FBI), were designed to emphasise that the time had arrived to celebrate and facilitate behaviour by staff that openly challenges existing regulatory structures and decisions, out of a regard for public welfare. ${ }^{1}$
Rhodes and Strain's paper, in this edition of the journal, focuses attention on the need for greater ethical oversight of behaviour in academic medicine. ${ }^{2}$ They mention a variety of personal, institutional, and historical factors that allegedly contribute to a lack of adequate internal investigation and resolution of misconduct in this area. A considerable literature supports their claims. ${ }^{3-8}$ The central message of their article, that transparency, honesty, and objectivity in the processing of such allegations are a sign of regulatory maturity, may have escaped many academic medical institutions.

\section{EXPOSING MISCONDUCT IN ACADEMIC MEDICINE}

One of FBI "whistleblower" Coleen Rowley's critical dilemmas, a point reiterated by Rhodes and Strain and explicitly illustrated in the cited Time magazine article, was that she, as a relatively junior legal professional at a field office in Minneapolis, had higher moral expectations of the organisation she worked for, than its senior management. ${ }^{1}$ Does this stark failing apply to many of our academic medical institutions?

If we include in our definition of academic medicine the bodies responsible for the authorising of credentials and for regulation which govern our professions, then the answer must undoubtedly be "yes". It is now well known that the presidents of the Royal College of Surgeons and the Royal College of Anaesthetists in the United Kingdom both knew about the problems of Bristol, but lacked the will to prevent children dying unnecessarily in the Bristol Royal Infirmary. Similarly in the Shipman scandal, colleagues of the convicted general practitioner (GP) raised concerns with the local health authority but were falsely reassured. ${ }^{10}$ It likewise took concerned and courageous doctors and nurses to blow the whistle in Winnipeg before a disastrous paediatric cardiac surgery service stopped putting children at the risk of unnecessary death or injury. ${ }^{11}$

Misconduct is apparently present in academic medicine from inception. ${ }^{5}$ Approximately $20 \%$ of applicants for gastroenterology or emergency department fellowships or residencies, who claimed prior publications, were found in separate studies to have fabricated either the article or the journal cited. ${ }^{12}{ }^{13}$ Questionnaires administered to students and faculties in academic research found that approximately $10 \%$ had direct knowledge of plagiarism by faculty members and $50 \%$ were aware of misconduct such as 
honorary authorship, sexual harassment, misuse of research funds, and violations of safety guidelines. ${ }^{14}$

On 2 June 2001 a healthy volunteer due to receive a $\$ 365$ honorarium, died from diffuse alveolar damage after participating in a study at the Johns Hopkins Asthma and Allergy Centre. The study involved inhalation of hexamethonium, a drug no longer in clinical use. The Federal Office for Human Research Protections determined that the institution's research ethics committee had been attempting ongoing review of up to 800 new proposals with biweekly meetings. It had kept no minutes for 18 of its last 21 meetings and failed to properly consider most protocols undergoing initial review. It had not attempted to inhibit a culture of "possible coercion" of employees and students to volunteer for randomised controlled trials. Staff at this prestigious institute of academic medicine must have known about the risks such regulatory defects were posing for research subjects, yet none came forward until an unnecessary death had occurred. ${ }^{15}$

Recently, in another high profile case from academic medicine, Drs Chen and He and Ms Ha, a PhD student, were forced to "whistleblow" on a public radio programme after internal regulatory processes at the University of New South Wales failed to adequately resolve allegations that a senior researcher, had, among other things, authorised for publication a paper containing duplicated and misleading data. The senior researcher was a professor of medicine at that university, a former president of the Australian Society of Medical Research and of the Transplant Society of Australia and New Zealand. Eventually the regulatory stamina and conscience of these individuals was vindicated by an external inquiry and a Supreme Court decision. ${ }^{16}$

Much work has already been done on enhancing the exposure of academic misconduct in relation to contracts, grants, and gifts from industry. ${ }^{78}{ }^{17}$ Legislation-for example, has been passed in some US states requiring academic staff to complete a financial disclosure form, which is a public document, obtainable through freedom of information statutes. This allows checks for possible fraud, such as use of public monies for private gain, conflicts of interest related to stocks or management positions, gifts linked to prepublication review of manuscripts, and loss of patent rights over research. ${ }^{18}$ Most academic institutions now have at least rudimentary policies concerning such matters. ${ }^{6}$

The US Commission on Research Integrity has defined misconduct relevant to academia as a "serious violation of the fundamental principle that scientists be truthful and fair in conduct of research and the dissemination of research results". Examples they gave included misappropriation (plagiarism or breaches of confidentiality), interference, misrepresentation (falsification or fabrication), obstruction of investigations of misconduct, and non-compliance with research regulations. ${ }^{19}$ This immediately raises the question of whether staff are being encouraged and supported in exposing apparently less perfidious practices, such as intentional or reckless misrepresentation of research results, failure to notify or explain weaknesses in data, selective reporting of successful results, quashing a negative study, or repetitive publication.

Rhodes and Strain emphasise that individuals courageous enough to inform academic institutions of inadequately investigated and remedied misconduct by colleagues almost invariably suffer dire consequences to their careers and their lives. ${ }^{2}$ The fact that when these "wronged" individuals do attempt redress from the media, extra-institutional inquiries or the courts they invariably succeed, might lead to the conclusion that the ethical, legal, and human rights expectations of society about dealing with such matters are much higher than those of the academic medical institutions themselves. ${ }^{2}$ What does research tell us about the nature of this gap between academic organisational and societal expectations of ethical behaviour in relation to the exposure of misconduct?

\section{OBSERVED INSTITUTIONAL RESPONSES}

The pathogenesis of fraud in medical science, its causes, investigation, and prevention have been the subject of official inquiry. ${ }^{3}$ Rhodes and Strain assert, however, that "little institutionalised energy has been directed towards the ethical oversight of academic behaviour per $\mathrm{se}^{\prime \prime} .^{2}$ They assert that the cause lies in a variety of personal, institutional, and historical factors. These have all been well documented in several countries. $^{3-5} 1920$ To a large extent they focus on the notion that a "whistleblower" is still presumed, by many with powerful professional regulatory positions, to be a disaffected, antisocial, incompetent pariah, "not a team player", who fails to appreciate the damage he or she is causing to the hard earned reputations of their professional colleagues and employer.

Professions are very protective of the status quo and individuals who attempt to question the activity of powerful or senior colleagues are inevitably seen as part of the problem, not part of the solution. This culture is reinforced during medical training to the extent that fewer medical students are prepared to undertake the ethically correct decision (to blow the whistle) at the end of medical training than at the beginning. ${ }^{21}{ }^{22}$ This behavioural change is attributed to the highly damaging "hidden curriculum" often established by those with power and prestige in medical institutions. ${ }^{23} 24$

In Australia, the Senate Select Committee on Public Interest Whistleblowing concluded that "whistleblowing" is a legitimate form of civil action within a democracy. ${ }^{25}$ Contrary to the popular institutional stereotype, the common pattern disclosed by research in this area, is that whistleblowers are typically motivated to report through standard internal channels in the expectation that this will resolve the problem and that their institution will support their attempt to expose the misconduct and improve the quality of service. External authorities are only resorted to once the whistleblower has reached the conclusion either that the organisation is amoral, or that senior management are torpid or complicit. ${ }^{26}$ The parallel with institutional responses to the Time magazine whistleblowers is illuminating.

Variable institutional responses, however, appear to routinely follow an instance of "external" whistleblowing. Rarely, the response is procedurally correct and in accordance with established clinical governance pathways. Commonly, the reaction is invisible obfuscation or silent inaction.

Frequently the institution's response is hostile, involving inappropriate strategies such as immediate notification of the complainant to the alleged offender, diversion of blame, psychiatric, and competence pillorying of the whistleblower and destruction of evidence. Veiled reprisals include formal reprimand, closer monitoring by supervisors, social ostracism, public humiliation, job transfer or gradual demotion, withdrawal of resources, exclusion from projects, denial of access to grants, and non-recognition of contributions to publications. Academic whistleblowers may be overlooked for promotion, and whispered about negatively in corridors and tearooms. Few are willing to support their allegations in public even when they know themselves to possess supporting evidence. Unemployment, bankruptcy, litigation, divorce, mental illness, and suicide are common outcomes of the act of whistleblowing. ${ }^{26}$

\section{DESIRED INSTITUTIONAL RESPONSES}

The expectation of the courts and therefore society in this area is quite clear. Whistleblowing individuals have almost 
invariably been exonerated and their employers required to re-instate or recompense them. This and the recent enactment in many jurisdictions worldwide of equivalents of the Public Interest Disclosure Act 1999 (UK), ${ }^{27}$ illustrates a general trend by law makers and the public to enforce and encourage the highest possible standards in medical academic institutions. In these circumstances the institutions of academic medicine must themselves realise and embrace the notion that only the highest possible standards are appropriate among their professionals and that open, expedited, and fair investigations of claims of scientific fraud or malpractice is the most satisfactory regulatory response. Perhaps they should now accept that whistleblowing will remain as essential a regulatory tool for academic medicine, as it will for clinical medicine.

The proposed solution of Rhodes and Strain draws on a system originating with the US Institutional Animal Care and Use Committees. ${ }^{2}$ This system, they maintain, involves assigning responsibility for misconduct to the institution, rather than any individual. Here is a valuable suggestion, one which might protect whistleblowers in particular from one of the charges commonly levelled against them, that of vindictiveness against a more favoured colleague.

The fact that the highest standard of practice is not always the goal in academic medicine may reflect the competitive financial behaviour and desire for greater reputation of these institutions and their senior staff. Perhaps, however, it is also an indictment of the personal and professional development training they received in medical school. Is it possible that proper instruction in the nature and importance of professional conscience and the ethical, legal, and human rights structures that protect and facilitate whistleblowing could prevent the problem?

\section{INITIATING PERSONAL AND PROFESSIONAL CHANGE}

How easy is cultural change in the conservative institutions of academic medicine? Our hypothesis is that the cure must start in medical education and that the problem of encouraging medical students to accept, if necessary, the burdensome role of whistleblower can be overcome in a relatively short period of training. This may not be possible in the six weeks that has been claimed to be sufficient for intensive training, professional, and technical support in anaesthetic registrars, ${ }^{28} 29$ but certainly it should be possible over the course of a four year postgraduate personal and professional development course which emphasises the importance of whistleblowing.

The approach at the Australian National University Medical School has been to design a personal and professional development curriculum in which medical students will be first systematically taught to understand the mix of fundamental ethical, legal, and human rights principles that justify the act of whistleblowing. They will be given personal exposure to courageous individuals who have followed their conscience to achieve regulatory reforms in medicine. In their final year they will be accorded the opportunity to experience a simulated, protracted, one year, whistleblowing experience. And, importantly, they will be given the opportunity to self audit their response to "near miss" adverse events with the utilisation of programmed personal digital assistants (PDAs). ${ }^{30}$

At Geelong Hospital, the strategy adopted to encourage whistleblowing in junior medical staff has been to target the registrar grade for a change in behaviour. It is interesting to note that at this level in the specialty of anaesthetics, registrars have been very enthusiastic to take up monitoring and reporting facilities when these have been provided. ${ }^{30}$ In effect the registrars are encouraged to "blow the whistle" on themselves and do so effectively in their training. ${ }^{28}$
From this it may be concluded that junior medical staff in the specialty of anaesthesia, but quite possibly in most specialties, might well enthusiastically commence and continue a programme of personal professional monitoring when the tools and supportive environment to rapidly and effectively collect appropriate data are provided, and their results are fed back in a secure, private, and usable fashion. ${ }^{28}{ }^{30}{ }^{31}$ Furthermore it appears that these registrars will report adverse events involving patients under their care if facilities are provided. ${ }^{28}$ 30-32

But perhaps even more important-and for us exciting-is the fact that registrars will also report incidents when they are worried that an adverse event might occur but when no actual adverse patient event has occurred. This is the "near miss" incident reporting data that revolutionised safety in the aviation industry and may be the "Holy Grail" of patient safety in health care organisations. ${ }^{33} 34$

What does this tell us about the future of medical student and junior doctor training in whistleblowing?

1) Despite the negative influence of the hidden curriculum of medical training on medical student attitudes we assert that the process can be reversed. ${ }^{28} 3132$

2) The reversal can be achieved by a process that combines teaching in medical ethics, law, and human rights, with medical humanities, and new information technology used to self audit.

3) The change in culture is profound and continuing provided the environment is supportive of the behaviour. ${ }^{35} 36$

4) The time taken for the change to manifest itself is short, possibly occurring in less than six weeks. ${ }^{28}$

Our conclusion is that if the problems in academic medicine are to be addressed properly the role of the whistleblower must come "out of the closet" and into mainstream medical education. Whistleblowing is conscience made active and "conscience" is a cornerstone principle of the foundational documents of medical ethics and a central feature of the "normative" approach to medical humanities that can no longer remain a "silent" area of the medical curriculum.

The Declaration of Geneva-for example, obliges a doctor to "practise my profession with conscience and dignity". ${ }^{37}$ In taking seriously our professional obligation as medical educators to train whistleblowers, we will finally be giving teeth to "practising with conscience", a regulatory obligation possibly hitherto disregarded in academic medicine and clinical medicine as mere whimsical phraseology.

The "good faith" whistleblower in clinical medicine should be promoted to medical students and among the profession as a true inheritor of foundational professional virtues, such as loyalty to the relief of patient suffering. This is supported by no lesser body than The World Medical Association in the International Code of Medical Ethics, which states that:

\section{"A physician shall, in all types of medical practice, be dedicated to providing competent medical service in full technical and moral independence, with compassion and respect for human dignity... . A physician ... shall strive to expose those physicians deficient in character or compe- tence, who engage in fraud or deception." ${ }^{\prime 38}$}

The expectation of the public and the profession, therefore, should be that behavioural change toward accepting and facilitating whistleblowing in mainstream medical education and practice is desirable and urgently required. We must begin to develop whistleblowing curricula and training 
programmes now. We must demand this change to existing educational and regulatory systems in months, not years.

\section{Authors' affiliations}

T Faunce, Medical School and Law Faculty, Australian National University, Canberra, Australia

S Bolsin, W-P Chan, Department of Perioperative Medicine Geelong Hospital, Geelong, Victoria, Australia

\section{REFERENCES}

1 Lacayo R, Ripley A. The whistleblowers. Time 2002 Dec 30:2-7.

2 Rhodes R, Strain JJ. Whistleblowing in academic medicine. J Med Ethics 2004:30:35-9.

3 Royal College of Physicians of London. Fraud and misconduct in medical research: causes, investigation and prevention. London: Royal College of Physicians, 1991.

4 Petersdorf RG. The pathogenesis of fraud in medical science. Ann Intern Med 1986; 104:252-4

5 Andersen D, Attrup L, Axelsen N, et al. Scientific dishonesty and good scientific practice. Copenhagen: Danish Medical Research Council, 1992

6 Bero LA. Disclosure policies for gifts from industry to academic faculty. JAMA 1998;279:1031-2.

7 Blumenthal D, Causino N, Campbell E, et al. Relationships between academic institutions and industry in the life sciences - an industry survey. N Engl J Med 1996;334:368-74.

8 Blumenthal D, Gluck M, Louis KS, et al. Industrial support of university research in biotechnology. Science 1986;231:242-6.

9 Bolsin SN. More on the Wisheart affair. BMJ 1999;318:1010-11.

10 Dyer O. Shipman murdered more than 200 patients, inquiry finds. BMJ 2002:325:181.

11 Sibbald B. Twelve deaths in Winnipeg: judge must ponder 48000 pages of testimony. CMAJ 1998;159:1285-7.

12 Sekas G, Hutson WR. Misrepresentation of academic accomplishments by applicants for gastroenterology fellowships. Ann Intern Med 1995:123:38-41.

13 Gurundevan SV, Mower WR. Misrepresentation of research publications among emergency medicine residency applicants. Ann Emerg Med 1996;27:327-30.

14 Swazey JP, Anderson MS, Lewis KS. Ethical problems in academic research. Am Sci 1993:81:542-53.

15 Steinbrook R. Protecting research subjects - the crisis at Johns Hopkins. N Engl J Med 2002;346:716-20.
16 New South Wales Supreme Court. Hall v University of New South Wales. Sydney, [NSWC 669] 15 August 2003.

17 Campbell EG, Louis KS, Blumenthal D. Looking a gift horse in the mouth: corporate gifts supporting life sciences research. JAMA 1998;279:995-9.

18 Political Reform Act. In: 2 Cal admin code 18705. Sacramento, California: 1974.

19 Commission on Research Integrity, US Dept of Health and Human Services. Integrity and misconduct in research. Washington DC, 1995: report no 746, p 42.

20 Farthing $M$, Horton R, Smith R. Research misconduct: Britain's failure to act. BMJ 2000;321:1485-6.

21 Goldie J, Schwartz L, Morrison J. A process evaluation of medical ethics education in the first year of a new medical curriculum. Med Edu 2000;34:468-73.

22 Goldie J, Schwartz L, McConnachie A. Students' attitudes and potential behaviour with regard to whistleblowing as they pass through a modern medical curriculum. Med Educ 2003;37:368-75.

23 Hafferty FW, Franks R. The hidden curriculum, ethics teaching, and the structure of medical education. Acad Med 1994;69:861-71.

24 Hundert EM, Douglas-Steele D, Bickel J. Context in medical education: the informal ethics curriculum. Med Educ 1996;30:353-64.

25 Senate Select Committee on Public Interest Whistleblowing. In the public interest. Canberra: Australian Senate, 1994.

26 Lennane KJ. "Whistleblowing." A health issue. BMJ 1993;307:667-70.

27 Anon. Briefing: The Public Interest Disclosure Act. BMJ 1999;319:3.

28 Bolsin SN. Whistleblowing. Med Educ 2003;37:294-6.

29 Bolsin SN. League tables and professionalism. Aust Health Rev 2001 ;24:1-4.

30 Bent $\mathrm{P}$, Creati B, Bolsin SN, et al. Professional monitoring and critical incident reporting using personal digital assistants. Med J Aust 2002;177:496-9.

31 Bolsin SN, Colson M. Making the case for personal professional monitoring in health care. Int J Qual Health Care 2003;15:1-2.

32 Bolsin SN, Solly R, Patrick A. The value of personal professional monitoring performance data and open disclosure policies in anaesthetic practice: a case report. Qual Saf Health Care 2003;12:295-7.

33 Reason J. Human error: models and management. BMJ 2000;320:768-70.

34 Vincent C, Taylor-Adams S, Stanhope N. Framework for analysing risk and safety in clinical medicine. BMJ 1998;316:1154-7.

35 Morton A. The use of statistical process control methods in monitoring clinical performance. Int J Qual Health Care 2003;15:361-2.

36 Colson M, Bolsin S. The use of statistical process control methods in monitoring clinical performance. Int J Qual Health Care 2003;15:445.

37 General Assembly of the World Medical Association. Declaration of Geneva. Geneva: General Assembly of the World Medical Association, 1948.

38 General Assembly of the World Medical Association. International code of medical ethics. Geneva: General Assembly of World Medical Association, 1949

\section{LETTER}

\section{Unheard heroes}

The online symposium concerning the Olivieri case provides a wealth of information, and lessons for the future. ${ }^{1}$ The articles, especially the one by Francois Baylis, ${ }^{2}$ and the e-letters concerning the articles, expand the teaching value of this case.

After reading both articles and letters I believe my own article requires a slight revision. As with others writing in the symposium, my assumption had been that while institutionally involved, Hospital for Sick Children bioethicist Mary Rowell was publicly silent about the affair. However, her letter details a public as well as an institutional advocacy.

"I was not silent, even at a very ordinary and public level," she writes. But her voice was not heard because, "I was simply not recorded in any detail".

The lesson is that the public (and academic) record is often incomplete, and those of us who write about the work of others must seek beyond that record, even to conversations with individual participants in cases like this. Let me therefore apologise to Mary

Rowell for any inadvertent slighting of her activity and position in this case.

Indeed if (as Francois Baylis suggests) we seek the heroes of bioethics, one might argue Mary Rowell's heroism. Indeed, few are as heroic as those who labour namelessly and without public or collegial regard, a condition that seems to describe her place in this affair.

T Koch

Adj Professor of Gerontology, Simon Fraser University, Vancouver, Canada and Adj Professor of Geography (Medical), University of British Columbia, Vancouver, Canada; Bioethicist, Canadian Down Syndrome Society (Resource Council) Calgary, Canada tokoch@attglobal.net

\section{References}

1 Olivieri symposium. J Med Ethics advance publications. http:// ime.bmjiournals.com/cgi/content/full/28/2/DC1

2 Baylis F. The Olivieri debacle: where were the heroes of bioethics? http:// ime.bmijournals.com/cgi/data/28/2/DC1/21

3 Koch T. Absent virtues: the poacher becomes gamekeeper. J Med Ethics 2003:29:337-42. 